\title{
Healthy lifestyle for metabolic health: no more excuse!
}

\author{
Katherine Esposito · Dario Giugliano
}

Received: 30 December 2013/ Accepted: 3 January 2014/Published online: 4 February 2014

(C) Springer Science+Business Media New York 2014

Eating alone will not keep a man well; he must also take exercise.

$$
\text { Hippocrates (460-370 BC) }
$$

Metabolic syndrome (MS) constitutes a growing problem worldwide. Whether or not one accepts this condition as a by-product of our modern lifestyle, the concept of MS continues to gain acceptance. There is a quite general agreement that its rising prevalence is largely due to the increasing incidence of obesity and associated lifestyle factors. The increased risk of type 2 diabetes and cardiovascular events in people with MS is well known [1]; recent epidemiological evidence also suggests a positive association between MS and the risk of some common cancer [2-4].

Studies of the beneficial health effects of physical activity (PA) date back to the 1950s [5] and have been replicated in large cohorts. Overall, PA is associated with many health-related benefits, including a reduced risk of developing several chronic diseases such as obesity, cardiovascular disease, type 2 diabetes, and cancer. Recommendations for PA and health have included $30 \mathrm{~min} /$ day (or more) of at least moderate-intensity PA on most days of

\footnotetext{
K. Esposito ( $\square$ )

Department of Clinical and Experimental Medicine, and Diabetes Canter, Second University of Naples, Piazza L. Miraglia 2, 80138 Naples, Italy

e-mail: katherine.esposito@unina2.it

\section{Giugliano}

Department of Medical, Surgical, Neurological, Metabolic and Geriatric Sciences, and Division of Endocrinology and Metabolic Diseases, Second University of Naples, Naples, Italy e-mail: dario.giugliano@unina.it
}

the week with respect to cardiovascular benefits [6]. Data from the U.S. National Health and Nutrition Examination Survey (NHANES) indicate that the vast majority of daily non-sleeping time is spent in either sedentary behavior $(58 \%)$ or light-intensity activity (39\%), and only $3 \%$ in exercise time [7].

Cross-sectional studies found an inverse gradient between amount of PA and MS. Guidelines support that at least 150 min of moderate-intensity PA per week is associated with a lower prevalence of MS and diabetes [8]. The EPIC Norfolk prospective population study investigated the association among PA, MS, and the risk of future coronary heart disease (CHD) and mortality due to CHD in 10,134 middle-aged men and women [9]. The prevalence of MS was $37.6 \%$ in men and $30.2 \%$ in women. There was no longer a significant difference in CHD event rate between men with MS who were active and men without MS who were inactive, indicating that PA lowers the CHD risk associated with MS.

$\mathrm{He}$ and coworkers [10] did the first meta-analysis of prospective studies, including 64,353 participants and 11,271 incident cases reporting the association between leisure-time physical activity (LTPA) and risk of future MS. Compared to inactive people, a high level of LTPA was associated with a $20 \%$ reduced risk of incident MS independent of sex, definition of MS, and duration of follow-up; on the other hand, the association between moderate level of LTPA and incident MS was modest (5\% reduced risk), except in men (12\% reduced risk) and in studies with a long follow-up ( $>10$ years). The aim to focus upon LTPA was not by chance: PA at work, walking, and bicycling have declined dramatically in industrial and urban societies. This is an important reason why more recent epidemiologic studies in high-income countries have focused on leisure-time activity, with less emphasis on 
work and methods of local transportation, which are important in developing countries. The meta-analysis of He et al. [10] parallels that of Kastorini et al. [11] showing that adherence to Mediterranean diets (clinical trials and prospective studies combined) was associated with reduced risk of MS (log hazard ratio: -0.69 ).

The Global Burden of Disease Study 2010 is the largest ever systematic effort to describe the global distribution and causes of a wide array of major diseases, injuries, and health risk factors. Since 1970, men and women worldwide have gained slightly more than ten years of life expectancy overall, but they spend more years living with injury and illness: non-communicable diseases, such as heart disease and cancer, become the dominant causes of death and disability worldwide [12]. The WHO global burden of disease (http://www.who.int/topics/global_burden_of_disease/en/) measures burden of disease using the disability-adjustedlife-year (DALY). This time-based measure combines years of life lost due to premature mortality and years of life lost due to time lived in states of less than full health. The burden of non-communicable diseases, both from the causes of years of life lost and the causes of years lived with disability, has been increasing in terms of the absolute number of years of life lost and years lived with disability and in terms of the share of the total burden over the two decades, with the largest increases associated with diabetes.

The leading risk factors changed substantially, and there were major shifts in the burden of disease between 1990 and 2010. The list of leading risk factors includes multiple components of diet, each of which were evaluated in isolation; taken together, all components of diet and physical inactivity accounted for $10.2 \%$ of global DALYs in 2010 [13]. Low dietary intakes of fruits, vegetables, whole grains, or nuts and seeds or a high dietary intake of salt are individually responsible for $1.5 \%$ to more than $4 \%$ of the global disease burden, with physical inactivity and low PA accounting for $2.7 \%$ of global DALYs [14]. Ironically, physical inactivity was not mentioned as risk factor in 1990 and was ranked 10th among the risk factors evaluated in 2010. Moreover, Mediterranean diet is being abandoned even in those countries (including Italy, Greece and Spain) where health-related benefits associated with its use have been demonstrated [15].

Time spent in sedentary behaviors (television viewing, overall sitting) is emerging as an independent risk factor for overall mortality, not necessarily for the time subtracted to PA. In the 240,819 U.S. adults (aged 50-71) of the National Institutes of Health (NIH)-AARP Diet and Health Study [16], high levels of PA did not fully mitigate health risks associated with prolonged time watching television: among adults reporting high levels of PA $(>7 \mathrm{~h} /$ week), high amounts of television viewing ( $\geq 7 \mathrm{~h} /$ day) remained associated with $47 \%$ increased risk of all-cause mortality, compared with those reporting the least television viewing $(<1 \mathrm{~h} /$ day $)$.

Despite the mounting evidence that unhealthy lifestyles lead to a host of metabolic diseases, and premature death, the majority of adults fail to meet nutritional and PA guidelines. We are apparently loosing the battle, as the incidence of lifestyle-related conditions (obesity, MS, and type 2 diabetes) continues to rise unabated. Western societies actually spend a huge part of their health care costs on chronic disease treatment and interventions for risk factors. Promotion of healthful lifestyles for primary prevention among individuals at all ages would yield great benefits and reduce the burden of non-communicable diseases. There is an urgent need for innovative, time-efficient, clinically effective strategies, coupled with changes in current attitudes and methods of delivering dietary and exercise prescription in order to improve metabolic health.

Conflict of interest The authors declare that they have no competing interests.

\section{References}

1. K.G. Alberti, R.H. Eckel, S.M. Grundy, P.Z. Zimmet, J.I. Cleeman, K.A. Donat, J.C. Fruchart, W.P. James, C.M. Loria, S.C. Smith Jr, International Diabetes Federation Task Force on Epidemiology and Prevention, Hational Heart, Lung, and Blood Institute, American Heart Association, World Heart Federation, International Atherosclerosis Society, International Association for the Study of Obesity, Harmonizing the metabolic syndrome: a joint interim statement of the International Diabetes Federation Task Force on Epidemiology and Prevention; National Heart, Lung, and Blood Institute; American Heart Association; World Heart Federation; International Atherosclerosis Society; and International Association for the Study of Obesity. Circulation 120, 1640-1645 (2009)

2. K. Esposito, P. Chiodini, A. Colao, A. Lenzi, D. Giugliano, Metabolic syndrome and risk of cancer: a systematic review and meta-analysis. Diabetes Care 35, 2402-2411 (2012)

3. K. Esposito, P. Chiodini, A. Capuano, G. Bellastella, M.I. Maiorino, C. Rafaniello, D.B. Panagiotakos, D. Giugliano, Colorectal cancer association with metabolic syndrome and its components: a systematic review with meta-analysis. Endocrine 44, 634-637 (2013)

4. K. Esposito, A. Capuano, D. Giugliano. Metabolic syndrome and cancer: holistic or reductionist? Endocrine. 2013 Sep 26

5. J.N. Morris, J.A. Heady, P.A. Raffle, C.G. Roberts, J.W. Parks, Coronary heart-disease and physical activity of work. Lancet $\mathbf{2 6 5}$, 1053-1057 (1953)

6. W.L. Haskell, I.M. Lee, R.R. Pate, K.E. Powell, S.N. Blair, B.A. Franklin, C.A. Macera, G.W. Heath, P.D. Thompson, A. Bauman, American College of Sports Medicine, American Heart Association, Updated recommendation for adults from the American College of Sports Medicine and the American Heart Association. Circulation 116, 1081-1093 (2007)

7. Centers for Disease Control and Prevention (CDC). 2010. National Health and Nutrition Examination Survey Data 20032004, 2005-2006. Centers for Disease Control and Prevention 
(CDC), National Center for Health Statistics (NCHS). Atlanta, GA. Available at: http://www.cdc.gov/nchs/nhanes.htm

8. M. Bergman, Pathophysiology of prediabetes and treatment implications for the prevention of type 2 diabetes mellitus. Endocrine 43, 504-513 (2013)

9. L.N. Broekhuizen, S.M. Boekholdt, B.J. Arsenault, J.P. Despres, E.S. Stroes, J.J. Kastelein, K.T. Khaw, N.J. Wareham, Physical activity, metabolic syndrome, and coronary risk: the EPIC-Norfolk prospective population study. Eur. J. Cardiovasc. Prev. Rehabil. 18, 209-217 (2011)

10. D. He, B. Xi, J. Xue, P. Huai, M. Zhang, J. Li, Association between leisure time physical activity and metabolic syndrome: a meta-analysis of prospective cohort studies. Endocrine. 2013;28 November 2013

11. C.M. Kastorini, H.J. Milionis, K. Esposito, D. Giugliano, J.A. Goudevenos, D.B. Panagiotakos, The effect of Mediterranean diet on metabolic syndrome and its components: a meta-analysis of 50 studies and 534,906 individuals. J. Am. Coll. Cardiol. 57, 1299-1313 (2011)

12. R. Horton, GBD 2010: understanding disease, injury, and risk. Lancet 380, 2053-2054 (2012)

13. C.J.L. Murray, A.D. Lopez, Measuring the global burden of disease. New Engl. J. Med. 369, 448-457 (2013)

14. S.S. Lim, T. Vos, A.D. Flaxman, G. Danaei, K. Shibuya, H. Adair-Rohani, M. Amann, H.R. Anderson, K.G. Andrews, M. Aryee, C. Atkinson, L.J. Bacchus, A.N. Bahalim, K. Balakrishnan, J. Balmes, S. Barker-Collo, A. Baxter, M.L. Bell, J.D. Blore, F. Blyth, C. Bonner, G. Borges, R. Bourne, M. Boussinesq, M. Brauer, P. Brooks, N.G. Bruce, B. Brunekreef, C. Bryan-Hancock, C. Bucello, R. Buchbinder, F. Bull, R.T. Burnett, T.E. Byers, B. Calabria, J. Carapetis, E. Carnahan, Z. Chafe, F. Charlson, H. Chen, J.S. Chen, A.T. Cheng, J.C. Child, A. Cohen, K.E. Colson, B.C. Cowie, S. Darby, S. Darling, A. Davis, L. Degenhardt, F. Dentener, D.C. Des Jarlais, K. Devries, M. Dherani, E.L. Ding, E.R. Dorsey, T. Driscoll, K. Edmond, S.E. Ali, R.E. Engell, P.J. Erwin, S. Fahimi, G. Falder, F. Farzadfar, A. Ferrari, M.M. Finucane, S. Flaxman, F.G. Fowkes, G. Freedman, M.K. Freeman, E. Gakidou, S. Ghosh, E. Giovannucci, G. Gmel,
K. Graham, R. Grainger, B. Grant, D. Gunnell, H.R. Gutierrez, W. Hall, H.W. Hoek, A. Hogan, H.D. Hosgood 3rd, D. Hoy, H. Hu, B.J. Hubbell, S.J. Hutchings, S.E. Ibeanusi, G.L. Jacklyn, R. Jasrasaria, J.B. Jonas, H. Kan, J.A. Kanis, N. Kassebaum, N. Kawakami, Y.H. Khang, S. Khatibzadeh, J.P. Khoo, C. Kok, F. Laden, R. Lalloo, Q. Lan, T. Lathlean, J.L. Leasher, J. Leigh, Y. Li, J.K. Lin, S.E. Lipshultz, S. London, R. Lozano, Y. Lu, J. Mak, R. Malekzadeh, L. Mallinger, W. Marcenes, L. March, R. Marks, R. Martin, P. McGale, J. McGrath, S. Mehta, G.A. Mensah, T.R. Merriman, R. Micha, C. Michaud, V. Mishra, K. Mohd Hanafiah, A.A. Mokdad, L. Morawska, D. Mozaffarian, T. Murphy, M. Naghavi, B. Neal, P.K. Nelson, J.M. Nolla, R. Norman, C. Olives, S.B. Omer, J. Orchard, R. Osborne, B. Ostro, A. Page, K.D. Pandey, C.D. Parry, E. Passmore, J. Patra, N. Pearce, P.M. Pelizzari, M. Petzold, M.R. Phillips, D. Pope, C.A. Pope 3rd, J. Powles, M. Rao, H. Razavi, E.A. Rehfuess, J.T. Rehm, B. Ritz, F.P. Rivara, T. Roberts, C. Robinson, J.A. Rodriguez-Portales, I. Romieu, R. Room, L.C. Rosenfeld, A. Roy, L. Rushton, J.A. Salomon, U. Sampson, L. Sanchez-Riera, E. Sanman, A. Sapkota, S. Seedat, P. Shi, K. Shield, R. Shivakoti, G.M. Singh, D.A. Sleet, E. Smith, K.R. Smith, N.J. Stapelberg, K. Steenland, H. Stöckl, L.J. Stovner, K. Straif, L. Straney, G.D. Thurston, J.H. Tran, R. Van Dingenen, A. van Donkelaar, J.L. Veerman, L. Vijayakumar, R. Weintraub, M.M. Weissman, R.A. White, H. Whiteford, S.T. Wiersma, J.D. Wilkinson, H.C. Williams, W. Williams, N. Wilson, A.D. Woolf, P. Yip, J.M. Zielinski, A.D. Lopez, C.J. Murray, M. Ezzati, M.A. AlMazroa, Z.A. Memish, A comparative risk assessment of burden of disease and injury attributable to 67 risk factors and risk factor clusters in 21 regions, 1990-2010: a systematic analysis for the Global Burden of Disease Study 2010. Lancet 380, 2224-2260 (2012)

15. K. Esposito, C.M. Kastorini, D.B. Panagiotakos, D. Giugliano, Mediterranean diet and metabolic syndrome: an updated systematic review. Rev. Endocr. Metab. Disord. 14, 255-263 (2013)

16. C.E. Matthews, S.M. George, S.C. Moore, H.R. Bowles, A. Blair, Y. Park, R.P. Troiano, A. Hollenbeck, A. Schatzkin, Amount of time spent in sedentary behaviors and cause specific mortality in US adults. Am. J. Clin. Nutr. 95, 437-445 (2012) 